\title{
Natural Sciences Teaching By using of ICTs to Individuals with Special Educational Needs
}

\author{
Maria-Theofania L. Kontopoulou, Athanasios S. Drigas
}

\begin{abstract}
Individuals with special educational needs have the right to enjoy the same quality of services in all areas of their lives and to have equal access to information and knowledge as their fellow human beings without difficulties. Information and communication technologies (ICTs) as a tool on these individuals' education can contribute in the best possible way to the development of their skills, to building the knowledge required and ensuring equal opportunities in their social lives with the effect of their self- esteem and self-sufficiency reinforcement and consequently their integration into society so that they can live in harmony and equality with all its members. This research is a bibliographic review focusing on the usefulness of Information and Communication Technologies in teaching of the Natural Sciences. The choice of topic was based on the attempt to inform for teaching of Natural Sciences through ICTs as an alternative way of learning for people with special educational needs. The results demonstrated that ICTs are valuable cognitive tool for children with special educational needs on natural sciences learning and also these are useful tool for teachers to be able to teach these sciences. The conclusion is that ICTs should be integrated in teaching of the natural sciences

Keywords: simulations- video games -virtual reality- ICTsassistive technologies- disabilities- autism- learning disabilities ADHD - deaf- hearing impairments- blind -visual impairment $A D D$,intellectual disabilities- Down syndrome -Natural sciencesphysics -chemistry -biology
\end{abstract}

\section{INTRODUCTION}

The last twenty years, the research on the study of the Natural Sciences learning and teaching has been developed to a great extent in order to find a suitable model for the teaching of these sciences. By improving teaching, students will discover that the Natural sciences are linked to the highest human achievements on a spiritual level as well as that these play a key role in major problems solving of contemporary life. In this way, they will be motivated to deal with these sciences so that tomorrow's citizens will be able to make the right decisions on a personal level but also for society in order to have a better future for humanity (National Research Council, 2012) [1]. However, while significant developments have taken place, the research concludes that these objectives have not been achieved due to the following reasons: The trainees a. don't have a deep understanding of basic scientific concepts b. they memorize knowledge only to know it and not to use it constructively c.

Revised Manuscript Received on December 05, 2020.

* Correspondence Author

Maria-Theofania L. Kontopoulou*, Net Media Lab-Mind \& Brain R\&D, Institute of Informatics and Telecommunications, N.C.S.R. 'Demokritos', Athens, Greece

Athanasios S. Drigas, Net Media Lab-Mind \& Brain R\&D, Institute of Informatics and Telecommunications, N.C.S.R. 'Demokritos', Athens, Greece

(C) The Authors. Published by Blue Eyes Intelligence Engineering and Sciences Publication (BEIESP). This is an open access article under the CC BY-NC-ND license (http://creativecommons.org/licenses/by-nc-nd/4.0/) solve problems in a specific way that they have learned mechanically without being able to think of alternative answers $d$. don't realize that the knowledge they gain from the study of science has a direct application in their daily life e. don't acquire internal motivations to improve their learning. (Shwartz et al.,2008) [2]. Research conducted in many countries shows that students form misconceptions about the concepts of the Natural Sciences andmisinterpret phenomena that occur in the natural world before the corresponding lessons are taught in school. According to studies, these misconceptions and wrong explanations are maintained in their adult life, despite the fact that they have often been taught inschool the concepts and interpretations of facts and phenomena in a scientific way. (Driver et al., 2014) [3] .The Natural Sciences teaching to individuals with special educational needs iseven less efficient because teachers don't receive the necessary scientific training to be able to discover these individuals' needs and abilities and use appropriate teaching strategies, adapt study programs and have realistic expectations resulting the achievement of the best possible effect. (Kirch et al., 2007) [4]. In addition, most laboratory infrastructures are all too often nonfunctional and even inaccessible to students with physical difficulties (Hilliard et al., 2013) [5] thus increasing the chances of being disappointed and giving up theeffort (Kirch et al., 2007) [4]. Thus, new learning environments creating is essential that will support these students' efforts and will provide them equalopportunities with their classmates without special educational needs for acquisition of knowledge.(Hadi et al.,2010) [6]. The new learning environments that are becoming more and more popular and more and morewidespread includethe use of technology in the educational process (Liu \& Tomasi, 2015[7]; Chantry \& Dunford , 2010 [8]; Hadi et al., 2010) [6] ) which according to the international literature proves to be a determining factor in effectiveness enhancing of learning for students with special educational needs for whom teaching is not effective when based on traditional educational programs. (Hadi et al.,2010) [6]. ICTs can greatly contribute to the successful students' with special educational needs response to all the requirements of the curriculum if the appropriate software tools are used which are accompanied by appropriate educational scenarios (Drigas et al., 2014)[9]]The rapid development of computer technology provides access to learning for every individual , at any time and in any place (Lawanto et al., 2017) [10] and is an important tool for education in development of critical thinking, problem-solving and collaborative learning achievement (Selvakumar \& Sivakumar, 2019) [11]. ICTs contribute to the provision of higher quality training to learners and strengthen them in acquiring the necessary skills and capabilities (Nefediev et al., 2019) [12].

Blue Eyes Intelligence Engineering \& Sciences Publication

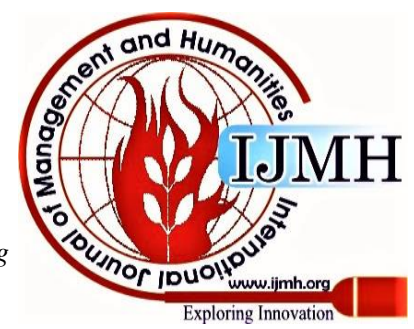


In recent decades, by technology using that provides flexibility, openness and accessibility to resources, strengths-based teaching and learning has been enhanced (Huda et al., 2019) [13].

Research studies conclude that ICTs should be used in education, communication and play for students with special educational needs (Chantry \& Dunford , 2010) [8].The integration of ICTs in teaching is a fun and interesting way of learning and their use is familiar to students but without degrading the quality and reducing the amount of lesson content. With the use of ICTs teachers achieve their teaching goals and students discover new techniques to build knowledge (Hadi et al.,2010) [6].

However, there is intense concern as, according to the studies the integration of the ICTs has not been achieved whether their use in the educational process is unsatisfactory (Wikan \& Molster, 2011 [14]; Judge, 2013 [15]) both in general education and in the case of students with special schools (UNESCO, 2011)[16]. The use of ICTs and by special education teachers is at a moderate level in frequency and doesn't yield satisfactory results (Nam et al., 2013)[17]. On the other hand according to the international literature, studies on the use of ICTs in people's with special educational needs education and integration are extensive in recent years. But most of them refer to the social and emotional support for these individuals and their improvement in mathematics and language (Istenic Starcic \& Bagon, 2014)[18]. There are very few studies on the use of ICTs for supporting students with difficulties in their progress in the Natural Sciences.

In this paper we reviewed studies on the teaching and learning of Natural Sciences by using of ICTs for primary, secondary and tertiary education. The purpose of this study is to investigate the contribution of Information and Communication Technologies as a tool for Natural Sciences teaching and learning in understanding of concepts, phenomena, facts and theories of these sciences from students with special educational needs. In particular, study aims to record software, applications, educational material based on ICTs, assistive technology and specialized ICTs tools used for various disabilities, resources provided to students and the ways in which they are used. Also it aims to examine how and to what extent the utilization of ICTs in teaching and learning of Natural Sciences affects the trainees' effectiveness.

\section{METHODOLOGY}

The present study is a bibliographic review that derives from searching for articles in international scientific journals. The investigation was conducted using keywords related to individuals with special educational needs and ICTs supported learning environments . The selected articles refer to teaching using ICTs and exclusively for individuals with special educational needs. All of articles that described teaching methods for the specific group of trainees but did not include ICTs were excluded. The reason why these articles were excluded is that ICTs is the ascending way of teaching for a generation who is excited, attracted and engaged in technology on a daily basis. Also all the articles that dealt with the use of ICTs but for general education were not incorporated into the study. The exclusion of these educational needs attending general education or in special

articles was done because the study focused exclusively on individuals with special educational needs who have not been given the necessary attention according to the international literature.

\section{INDIVIDUALS WITH SENSORY AND PHYSICAL DISABILITIES}

\section{A. Deafness and Hearing Impairments}

Zamfirov et al. (2007) [19] created the multimedia sign dictionary 'Humans and nature, physics and astronomy' for physics and astronomy teaching to hearing impaired students who attend at mainstream or specialized junior high schools in Bulgaria. HTML and Javascript were used for CD creation . The signs are shown in FLASH clips.. This dictionary analyzes basic terms accompanied by textual explanation and various illustrations and uses Bulgarian, English and Bulgarian Sign languages. So students understand more easily terms, physical processes and phenomena through visual representation and lip-read terms in English and Bulgarian. Also inserts bilingualism to help hearing impaired students who have been integrated in mainstream schools, raises people's interest without hearing disabilities for the ways in which deaf people understand the world and proves that deaf 's teachers must ensure that the images are as realistic as possible, providing an incentive to study the world, the Earth, the universe and all the laws and rules we obey.

Robinson (2013) [20] presented the 3-D virtual world of Second life, that is applied to deaf college students to practice acceleration concept first encountered in the real lab. Each student is represented and controls an avatar that interacts with the virtual world and with the other students' avatars using a computer with appropriate viewer free software. Students can do the lab wherever, as long as they want, as many times as they want. They can meet and work together whenever, even if the distance between them is great, but also to cooperate with their instructors. Students' virtual lab experiences were integrated with Webassign, an online homework and testing site with immediate feedback about students answers. Using Second life that resembles the real life labs, students integrate real labs experiences to their homework problems and manage to complete them. So they get good grades and have incentive to learn physics. Second life is also used for uniform circular motion, Archimedes Principle etc. Egelston-Dodd \& Ting (2007) [21] used a web-based astronomy course for first year deaf college students that aims to address the insufficient literacy skills of deaf students in science. A digital video camcorder that was used to videotape an American Sing Language interpreter as he signed the lesson was linked to a PC via a Firewire cable to digitize and save the video as compressed file. As well slides were created which involve animation and short clips of text taking content that exists in web site. Slides and video were uploaded to IdeaTools, a web authority/course management system and were synchronized so these would play in time. With this way students learned the technical vocabulary and definition, reduced astronomy misconceptions a fact that shows that by using of Webbased technology deaf students can attend mainstream classes.

Blue Eyes Intelligence Engineering

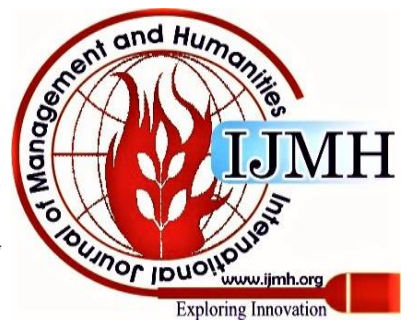


Bogusevschi et al. (2018) [22] applied the educational application Water Cycle in Nature to students of two first year classes in a secondary school which is mainly used for students' familiarization on concepts of vaporization and condensation and their importance for the water cycle in nature and the precipitation formation. Also definitions of evaporation and boiling are provided . Application includes a 3D immersive computer-based virtual reality environment for the water cycle in nature which depicts a natural environment consisting of a lake and a forest and one pilot activity in a $360^{\circ}$ virtual lab enabling students to run two separate immersive multimedia 3D simulation experiments on the phenomenon of condensation and vaporization. Application is suitable for students hearing impairments and is available on Windows and Android devices. Students follow instructions given either as text displayed on the screen or as oral information and sign language is used for hearing impaired students when it is necessary. The findings showed that the experimental group the video game GameOhm with accessibility features in order to help students with hearing disabilities who study in second year of electronics engineering to understand the concepts of current, voltage and resistance that related to Ohm's law. The game supports player to learn what is needed to understand the concepts.. Font type and size adjustment helps user to read more easily, not tire his/her eyes and be informed about the environment. Sign language enhances user in game description and Unified Software Development Process or Unified Process (UP) methodology UP uses Unified Modeling Language (UML). Serious game was installed on six Samsung Galaxy Tab S2 with Android Marshmallow 6.0.1., was tested on first semester twenty-two students and gained their interest and acceptance. All of them understood current and resistance concepts and half of them understood voltage concept so should be improved all information for voltage or should be used another more target example for it.

Choiriyah (2015) [24] created an interactive e-book for high school deaf students that is mentioned in material of chemical in everyday life and investigated its feasibility upon criteria of content, language, and presentation. Furthermore research focused on five deaf students' response about the e- book. All of students knew computer manipulation. Research was attested by a lecturer of chemistry, a special need lecturer, and a science teacher who defined the feasibility of e-book. Designing storyboard of e-book was created by using of bibliografic study and school research data. Subsequently making of contents that was based on storyboard. Contents consists of matter, pictures, videos, sign language videos. According to the results of the evaluation the e-book is very feasible with the presentation getting the highest percentage, the second highest percentage was for the content while the language percentage was smaller than the previous two. Also students' response was very positive. knowledge were improved significantly after using of application. Jaramillo-Alcázar et al. (2018) [23] presented instructionsunderstanding. Subtitles are appeared in simple language for students. Game Ohm was developed with

\section{B. Blindness and Visual Impairments}

Goncalves et al. (2017) [25] described an experimental setup in order to help blind students to conduct the simple pendulum experiment. This setup consists from a pendulum and a system that converts distance in sound frequency. In particular an ultrasonic sensor (model HCSR04) and a computer speaker were connected to an Arduino Nano 3.0 board. Because sensor detects the bob's position is placed front of pendulum. When pendulum starts to move bob distance is measured by sensor, is read by Arduino Nano that converts a range of distance to sound with a frequency range between 500 to $3000 \mathrm{~Hz}$ that is output from a computer speaker. So blind student can understand the periodic movementmechanism of a pendulum that performs harmonic oscillation. Successful conduct of experiment requires the coexistence between students who have normal vision and students and blind students. Students without blindness will set up and adjust the pendulum. Subsequently they will provide the necessary information to their blind classmates for the setup and blind students will then interact with the experiment. Qutieshat et al. (2019) [26] described a simple Arduino-based pH sensor (Design-Bee Sensor) for students with visual impairments in chemistry laboratories that is user-friendliness, has miniature size and flexible coding. This device is easily and economically manufactured and consists of an Arduino Uno microprocessor (Rev3 Arduino) that is connected with a Red-green-blue (RGB) color sensor with IR filter and white LED and a Piezo-electronic buzzer, Breadboard wires, $5 \mathrm{~V}$ power supply, universal $\mathrm{pH}$ paper , 3D-Printed spillage-resistant . Changes in color of $\mathrm{PH}$ paper depending on $\mathrm{PH}$ of analyzed solution are detected by the RGB color sensor and the number of generated output tones is programmed to be equal to the $\mathrm{PH}$ value the sensor detects. Students can also actively engage to more meaningful $\mathrm{pH}$ paper exercises for gaining richexperiences, thereby enhancing their self-esteem and belief that they are equal to their peers. So the integration of these students into learning processes are promoted. Such devices provide a useful and exciting laboratory experience not only for these students but also for their peers without disabilities. Quinn (2012) [27] designed and presented the " Walk on the Sun ", an interactive experience of image that is converted into music. The explorer is walking or moving over an image of the Sun. Pictures of the Sun are projected onto a white floor. In the first stage, visitor's movements are visually detected, recorded by a visual surveillance software and used for pixels selection of the image. In the second stage, the content of the pixels is converted into music in real-time that is hearing from individual. Color is mapped to one of nine musical instruments and brightness to one of 50 pitches. MIDI (Musical Instrument Digital Interface) controlled internal or external synthesizers are used for this conversion. Music contains melodies or chords from instruments such as guitar, piano, steel drums, etc. So people with blindness can explore images of the Sun from the STEREO (Solar Terrestrial Relations Observatory) mission, nebulae, and galaxy images from the Hubble Telescope as well as art masterpieces. 


\section{Natural Sciences Teaching By using of ICTs to Individuals with Special Educational Needs}

The results of " Walk on the Sun 'applying to 65 blind students showed that their color understanding was relatively easy. Most students could map at least one color in one session and identify colors in pictures. Morgan \& Moore (2016) [28] incorporated keyboard navigation and auditory descriptions into the existing PHET simulation Capacitor Lab: Basics for high school and undergraduate students with visual impairments. A Capacitance screen displays a battery and a capacitor in a circuit, a capacitance bar graph, a control panel for changing the values of experiment physical quantities. A Light Bulb screen displays additionally a light bulb in the circuit, and options to view bar graphs for plate charge and stored energy. Students understand the capacitance dependence on plate area and separation, the relationship between voltage, charge, stored energy and capacitance and how capacitor discharges and charge reaches in lamp. Students using only the keyboard input can navigate and interact with sim. Audio descriptions obtained with screen reader software provide verbal information on all settings and features and dynamic feedback. By moving the focus around the screen using the keyboard students understand what they can do with sims and explore their conceptual questions. According to results students interact and understand fundamental physics concepts without need of detailed instructions. Cole and Slavin (2013) [29] presented a modern video technology in order to help a student with low vision to participate almost completely in University's program in experiments. Student chose the Acrobat Panel and the Long Arm. Acrobat Panel is a 19-inch LCD monitor and the Long Arm is an articulated arm that features a built in autofocus video camera at its end. Camera can be mounted anywhere in a 60-centimeter radius, focus on objects that are within a few centimeters of up to 50 meters and magnify them up to 72 times using a remote control. There is also choice of contrast and color brightness. During the experiment when the camera was in a position it could be locked and was able to maintain position, focus and magnification. This allowed the student to perform a task with his own hands while viewing the LCD screen. So student can perform laboratory exercises independently. Using USB bridge camera is connected to a laptop or desktop via the USB port and the computer screen can be split and show both the camera images and computer output so user can use the computer to type notes or enter data while observing the camera material . Nazemi et al. (2015) [30] described a chemical equations Balancing method for vision impaired students. In particular they used the idea of Chemical Markup Language - CML XML a mainstream approach that offers semantics for a wide range of chemical concepts, to convert unbalanced chemical equation to a Mark-up format by adding basic tags. The representation of these equations provides the ability to navigate through the classified data such as species , elements, numbers of quantities at the left and right part of equations, reactants, and products. In this way, blind students will be able to find the right coefficients to balance the chemical equations without having to create mathematical equations and remember a large amount of information. Linux Bash Script was used for the representation in Mark-up format. Bash has enough chemical physics that requires physics laboratory

powerful text manipulation tools in command line mode so can receive an unbalanced chemical equation as an input, processes, classifies information and represents it as Markup format or Alternative Audio Descriptive using Text to Speech. According to the results application is trustworthy for chemical equations balancing therefore can be used from students.

\section{Motor Disabilities}

Tsavli et al. (2009) [31] designed an ICTs system for Physics teaching to students with kinetic disabilities in a robotic physics laboratory. Each registered user in Robot Control Station (RCS) of system has personal profile database with all necessary adjustments of interfaces and robotic arm for their rapid calibration which depends on type of user's kinetic disabilities. RCS reads a new experiment or a stored one and via a robot control interface guides the robot arm that has RFID reader to place the necessary items that have RFID at the absolutely right place. Users can perform the experiment by manual use of robotic arm or by programming of it using a High-Level robot Language. Remote students connect to the Virtual LAN of the lab platform via World Wide Web, logins to the platform, loads his/her profile, prepare and perform an experiment by remote control functionality. Users observe the real-time experiment performance through the cameras with real conditions and reliable results. Duarte et al. (2008) [32] used the Universal Virtual Laboratory (UVL) for students who have limited or no use of their hands and arms. UVL aim is to provide them a self-paced realistic lab experience and a smart lab assistant for directions and feedback. It analyzes dc, ac, transient circuits, is used as a pre-lab experience or as part of distance learning and uses adaptive technologies such as large keyboards, voice recognition etc. User interface consists of a breadboard with miniature instruments and electrical components that are connected in the breadboard holes when user chooses instrument or component and inserts the hole coordinates in which he wants to connect acable. Via the Dragon Dictate voice interface students use a packaged Authorware to control the instruments and lay out or set up a circuit. Pspice software analyzes the circuit, stores the analysis data which coming out of Pspice output are processed and displayed from LabView software. UVL was first applied to undergraduate students without disabilities and was found that is user-friendly and all in all students were satisfied it. A specialist in adaptive technology deduced that UVL enables physically challenged electronic labs users to access realistically simulated electronics equipment without being in the labs. Gerhátová (2014) [33] presented the implementation methodology of real remote experiment on the internet "Mathematical pendulum" because physically challenged students can conduct such experiments anywhere, anytime and many times. She performed a project assignment, the use of a freely accessible e-experiment from University of Trnava e-laboratory, one also freely accessible virtual experiment and applied them to future physics teachers.

Published By:

Blue Eyes Intelligence Engineering

\& Sciences Publication

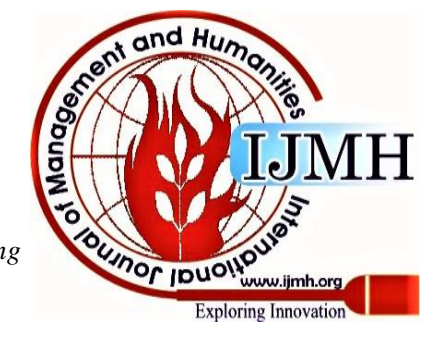


The aim of the project was pupils to use internet and find specialized literature in order to identify the necessary information, gather it and assess its accuracy. Also discuss, collaborate, suggest solutions, accomplish the assigned tasks part, follow the information process in the selected form, present the information in full and connect what they learned in everyday life. As well distinguish the dependent variables from independent, calculate the gravity acceleration in Trnava by processing of remote experiment data and learn Slovak, English. The work was individual and was done in one week. Information retrieval websites were provided. The results showed that students' performance needs further processing but their interest in technology involvement in everyday life ever growing.

\section{INDIVIDUALS WITH COGNITIVE DISABILITIES}

\section{Intellectual Disabilities -Down Syndrome}

Kyriakou et al. (2015) [34] researched whether multisensory approach through using of ICTs can help a first-year mainstream secondary school student with Down syndrome (D.s.) and mild intellectual disability to join in Biology course namely plant reproduction. While professor was presenting lesson to the class by a website using projector and laptop special education teacher was helping him using a vocabulary to explain the terms and an ipad in exhibited a real flower passing by each desk and each student showed and named it's parts. Next he painted three different flowers on the whiteboard and picked up pupils to write their parts. Student with D.s. and his teacher followed the same process through the ipad painting program. He could now identify the plant parts. Students groups met after school, found information from internet, created power points that they presented and each group made a poster with printed images. The student with D.s. was examined using his ipad in an activity from an interactive biology book. In lessons were used the Kidspiration, google images and maps, YouTube, Ministry of Education e-books and educational software. So the student made spectacular advance and joined the general class.

Tomlinson et al. (2018) [35] incorporated audio elements in $3 \mathrm{PhET}$ simulations for high school individuals with intellectual and developmental difficulties. "John Travoltage" and "Balloons and Static Electricity" were used for static electricity. In first one students moves John's leg on the carpet listening a realistic "rubbing" sound and accumulate negative charges on his body hearing short tone with ascending pitches as the charge is increasing. Moving his arm towards or away from a doorknob causing the charges to move to it resulting in a "zap." In second one when a balloon is rubbed on a sweater negative charges are transferred from sweater to balloon and it will stick on sweater upon release. If balloon moves near a part of a wall this part acquires a positive charge. The volume of a pulsing tone indicates the increase of balloon charge. Another short tone increases its frequency depending on the charge being transferred. In "Build an Atom" students drag protons, neutrons, electrons from buckets into the atom model hearing ascending and descending tones that which was displaying the website content. Professor

represents their electing and releasing and looking information for the built-in atom. For a new built-in element type two tones play together. The results showed that students were happy, interacted and explored successfully by the sims. Many of them understood all issues mainly after prompted tasks completion.

Kim (2017) [36] researched the effects of interdisciplinary approach by using multimodal modeling activities using technology in teaching and learning of astronomy thematic unit "day and night" to students who had motor disabilities which ranged from great difficulty controlling their muscles to mild speech impairments owing to the intellectual disability. ICT integrated storytelling activities were designed in which students can exchanges experiences, feelings, beliefs and challenges around the story events, so they could build their own understanding of the causes of day and night. Then children using verbal expressions, drawings with volunteers help and their teachers' guidance and encouragement communicated, and became collaborators or co-participants who coconstructed meanings for the theme . Next students could to think about how to place 3D physical models such as the sun, earth and moon to represent the day-night cycle and find the explanation of it through guided questions and disproved wrong ideas. Finally, students took on the roles of Sun, Earth, Moon, Day and Night and other roles to participate in modeling activity using body movements and thus to further ensure their understanding of the day and night cycle.

\section{B. Learning Disabilities}

Marino et al. (2014) [37] applied to middle school students with learning disabilities traditional teaching methods for some science units and the games Cell Command for cell anatomy and functions, Crazy Plant Shop for genes and inheritance, You Make Me Sick! For bacteria ,viruses and Reach for the Sun for photosynthesis, plant life cycle. Games were aligned with CAST UDL (Universal Design for Learning) Version 2.0 guidelines that require multiple means of representation, action and expression, engagement. In Make Me Sick! Students analyzed a virtual host's features and then chose a readymadepathogen or made their own pathogen providing them with multiple means of action and expression. They carried the pathogen in the host's body, left it , went to the cellular level trying to stay away from white blood cells and completed the infection process. This journey and a virtual dictionary that included a read aloud option and page numbered links to supplemental PCI science materials aligned with UDL provided multiple means of representation. Students highly engaged during UDLaligned units. There were no significant differences on posttest scores between students with LD and their peers without LD. Posttest scores after the UDL-aligned units wasn't significantly different from those after units taught by traditional methods probably due to limited playing time.

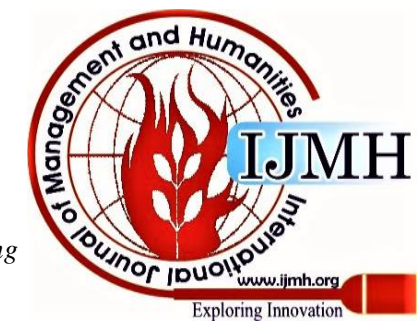




\section{Natural Sciences Teaching By using of ICTs to Individuals with Special Educational Needs}

Marino et al. (2011) [38] in collaboration with Filament Games, created the game "Body Command," to explain how middle school teachers can sharpen students' with learning disabilities science performance using video games those align with Universal Design for Learning (UDL). It allows these students to interact with and learn about the cells, tissues, organs and complex chemical reactions that take place inside the human body. The player controls the command center for each human body system on a rotating base so can be rotated between command centers. Each student can play easy either individually or be part of a team. Players as gradually increase their level after evaluation, are asked to solve even more complex problems such as viral or bacterial infections, parasitism, starvation, and organ failure. Finally they learn to engineer improved body systems and create a bionic human. During the game they can test some actions and get instant feedback. It allows students to experience science in visual format that leverage of each child's unique capacities. Researchers point out that while video games improves science learning outcomes, doesn't mean that those replace other well-designed curriculum materials. Vassilopoulou \& Mavrikaki (2016) [39] studied an $\mathrm{AD} / \mathrm{HD}$ student's behavior during biology lessons. A lesson for Lamarck's theory without ICTs' use took place in 4 phases: a. introductory information b. teacher's questions c. Reconstruction of students' ideas through explanation using appropriate worksheets. D. explain examples. A lesson for Darwin's theory with ICTs' use was done in 4 phases too : a. introductory information using a PowerPoint file b. students' ideas using questionnaire was projected on the interactive whiteboard. C. Reconstruction of student's perceptions using the 'PhET: Natural Selection (PHET sims) 'and 3 activities with worksheets d. Pupils analyzed the natural selection's mechanisms in certain examples performed activities. AD/HD student preferred ICTs lesson and understood the concepts better. His distraction from external stimuli was reduced and he was willing to participate more focused in the learning process. His hyperactivity appeared the greater decrease. Impulsivity improvement was less noticeable. But according to researchers and $\mathrm{AD} / \mathrm{HD}$ student the combination of good teaching and ICTs use could increase student's performance. Ma \& Zhang (2019) [40] examined the undergraduate student's performance with learning disabilities (LD) in college physics. A studentcentered hybrid teaching mode based on massive open online courses (MOOC) combining online and offline learning is applied to experimental class. Students with LD rarely preview before class, so an evaluation system is used which embodies the time of using MOOC video preview course content into the performance evaluation before class. The interactive immediate feedback system clicker enhances students' engagement and initiative. Before class students using textbook and MOOC preview learn autonomously, participate in online learning and discussion, ask about required tasks, so consolidate the knowledge being taught. Teachers focus on the important content and the students' questions in the classroom and devote more time than traditional teaching in classroom practice and students' ideas expression about this theory through Students analyzed the theory mechanism and tried to

discussion. The control class is taught in the traditional way mainly by lecture. All students are satisfied with their teachers' teaching performance. Many students find that teaching based on MOOC yields better learning outcomes for all students. Especially for students with LD it is significantly more efficient than traditional teaching and increases their interest in learning physics. Baumann \& Melle (2019) [41] designed and examined the effects of a learning software using the UDL for lower secondary students with and without special educational needs (SEN) most of whom had learning disorder. They used the teaching method of Exposition that focuses the presentation of the teaching content. For learning software developing the authoring software is called Mediator 9.0 (MatchWare A/S, 2016) was used which allows student to interact. The first part of learning software deals with Chemical reaction, Chemical equation and Physical process and the second one analyzes the Oxidation, Constancy of mass and Submicroscopic level. Every topic includes digitized information input, self-assessment sheets various tasks by immediate feedback and information texts that students need to complete to proceed to the next topic. Real experiments are being performed. For the data that emerged from a performance test and a posture test completed by the students the Wilcoxon-test was used. Videos that recorded selected students activities were analyzed with the software MAXQDA. According to the results the learning software is helpful for students with and without SEN, who learn in an ndividualized and differentiated way on a common learning object.

\section{Autism Spectrum Disorder}

Cecil et al. (2017) [42] applied to 9 elementary autism students from grades 2 to 6 the Solar System Module that is a semi immersive environment . In this environment student can know and interact with a 3D Virtual Reality (VR) environment wearing stereo eyewear. Because of the projection screen is only in front of users if they want to can turn and see at the real world. The Solar System Module provide to students introductory knowledge for various planets in the systems, their relationship with the sun and learn them basic concepts for rotation and revolution. Pretests and post-tests were used. During the post-tests two second students didn't correctly answer two questions after one attempt of learning through Virtual Learning Environments (VLEs ) interactions. They had the opportunity to go back and interact with the VLEs as many times as needed. After two more times they managed to answer all questions correct. Further such VLEs must be developed supporting university autistic students. Tolentino et al. (2009) [43] described a SMALLab learning scenario for students on the autistic spectrum . SMALLab is a mixed reality environment where participants interact face-to-face in an intermediate space. CAST's universal learning design (UDL) guidelines, MEDIATE project methodologies and findings, a SMALLab experiment were used.

Blue Eyes Intelligence Engineering \& Sciences Publication 
A scenario for titration and neutralization understanding was applied to high school students without disabilities contained audio cues and visual displays to represent chemical information in a variety of ways. Because of students had an improvement in their comprehension, engagement, reasoning and spatial reasoning skills, collaboration and constructive environment use to learn, this work extended for autistic students to be examined how they can engage in SMALLab. Initially, students' behaviors was observed using the "thick description" method. A comfortable scenario for the whole class was developed. Experimental interactions in a SMALLab environment were created for students which let them to choose musical, visual preferences. Music plug-ins based on their choices written using Jsyn and visual plugins developed in Objective C language/Open GL using visualization software by L. Olson (AME faculty). King-Sears et al. (2015) [44] applied Universal Design for Learning (UDL) treatment or a comparison condition to general education students (GED) and students with high-incidence disabilities (HID) of which one with autism, in high school for molar conversions teaching. Calculating Mole Conversions pre-test, post-test, and delayed post-test were used. For UDL Mole Module classes Camtasia software video clips with animation , highlighting features arrows or underlining were used. 3 video clips dealt with Avogadro and chemicals molar mass calculating. 1 described the IDEAS self-management strategy for the multi-step mole conversion process, with 5 dealing with solving one- , two- , both one- and two- steps conversions process. Graphic procedural facilitators for conversions support using IDEAS were made. Mole Student Workbooks (MSW) contained slides from each video clip and multiple copies of answer keys for the practice problems, a laminated strategy with information for conversions and a Mole Equality Organizer for the 3 mole equalities were used. The results showed that UDL treatment may potentially enhance the students with autism and the other disabilities but it's not effective for GED students. So it must be improved to address all students' learning needs.

\section{CONCLUSION-DISCUSSION} the impact of ICTs using in the teaching and learning of the Natural Sciences to individuals with special educational needs. There was improvement in students' performance after the use of ICTs. Their best performance was shown by the higher post-tests score after the use of ICTs (EgelstonDodd \& Ting, 2007[21]; Bogusevschi et al.,2018[22]; Cecil et al., 2017[42] ) and according to the students themselves (Marino et al.,2014[37]; Vassilopoulou \& Mavrikaki ,2016[39] ). It should be noted that this improvement was related both the better understanding of the material (Zamfirov et al.,2007[19]; Egelston-Dodd \& Ting, 2007[21]; Bogusevschi et al.,2018[22]; Jaramillo-Alcázar et al. 2018[23]; Morgan \& Moore ,2016[28] ; . Tomlinson et al.,2018[35]; Kim, 2017[36] $-($ ) and the number of students who understood it better (Bogusevschi et al.,2018) [22].

The students were motivated to engage in the Natural Sciences (Robinson , 2013[20]; Kim, 2017[36] ; Ma \&
The present study leads to very important findings about

Zhang,2019[40]) and there were cases in which their increased motivation affected positively not only their attitude towards Natural Sciences in their student course but also the continuation of their studies in these sciences. A typical example is one of the studies where blind students were surprised realizing that they could conduct the laboratories with autonomy and stated that they wanted to engage in science (Wedler et.al., 2014) [45]. If students with blindness or low vision participate in practice in more experiences they will believe that they have the ability to participate in laboratory experiments actively so they will study and work in the Natural Sciences but also in mathematics and technology (Supalo et.al., 2009) [46]. The individuals' with special educational needs knowledge gap from their peers was decreased because the use of ICTs offers immediate experience, personalization, access to learning spaces for students who did not have this opportunity before , such as blind (Qutieshat et al.,2019) [26] , deaf or with mobility difficulties children (Gerhátová , 2014) [33]. Blind or deaf pupils in most cases were passive recipients of knowledge without the use of ICTs while with the help of technology they participate in the learning process actively and autonomously (Cole \& Slavin ,2013) [29]. Students with motor disabilities were not able to be in the laboratory place while the technology allows them to be in the learning area and participate in laboratories independently and in the learning process from a distance as if they were in real laboratory space (Tsavli et al., 2009 [31]; Gerhátová,2014[33]) . Also, each student learns at his own paces but at the same time interacts with his classmates and teachers and can attend generalschools (Egelston-Dodd \& Ting,2007[21] ; Kyriakou et al. ,2015[34] ; Baumann \& Melle,2019[41]). The teacher's presence was necessary in all cases. The teacher encourages the students, answers the children's questions, chooses the material (Zamfirov et al.,2007[19]; Robinson ,2013[20]; Kim, 2017[36]; Marino et al. ,2011[38] ) , coordinates them not to deviate from the purpose of the process, for example in games the children may be so excited that they learn the game but not the knowledge contained in it. The teacher is considered the helper of knowledge from the pupils (Kim, 2017) [36]. The student with ADHD considered the traditional teaching necessary despite the fact that the course with ICTs excited him and increased his attention and his participation in the learning process (Vassilopoulou \& Mavrikaki, 2016) [39] . Many times for better results as shown by some studies the teacher combines the using of ICTs with other teaching methods such as differentiated teaching in student's with Down syndrome case ( Kyriakou et al., 2015) [34]. ICTs strengthen individuals' with special educational needs inclusion because all studies indicate that independence, autonomy (Cole \& Slavin , 2013[29] ; Ma \& Zhang, 2019[40] ) , communication and collaboration with their classmates (Egelston-Dodd \& Ting, 2007[21] ; Robinson ,2013[20]; Goncalves et al.,2017[25] ; Morgan \& Moore ,2016[28]; Kyriakou et al.,2015[34]; Kim, 2017[36]; Marino et al. ,2014[37] ; Marino et al. ,2011[38]; Vassilopoulou \& Mavrikaki 2016[39]; 

personalization and immediate feedback ( Egelston-Dodd \& Ting, 2007[21] ; Robinson ,2013[20]; Morgan \& Moore ,2016[28]; Marino et al. ,2011[38] ; Ma \& Zhang,2019[40] ; Baumann, \& Melle, 2019[41] ) are supported. Students gain confidence, self-esteem and feel that they have equal opportunities in knowledge with their classmates without disabilities (Qutieshat et al.,2019)[26]. There were no negative effects from the use of ICTs.

\section{LIMITATIONS-FUTURE RESEARCH}

The first limitation in this review is the limited number of studies available on this topic. The second limitation is that the present paper included bibliography only in English language. Another limitation is that the results of the research agree with each other so there is no comparative study between the findings. Based on the second limitation of the research, it is possible to further study the subject bibliographically. Taking into account the first limitation , it would be useful other qualitative and quantitative studies to be conducted for all children's cases with special educational needs so that there is a larger sample and therefore more reliable results regarding the way in which ICTs affects students' performance in the Natural Sciences and their rate of influence. It would also be interesting research to be conducted in which a specific category of technology will be applied to different learners' ages in the Natural Sciences who have the same disability . This would make it clear what kind of technology is appropriate for each age group in order to better learn the Natural Sciences. It would also be good studies to be conducted which will explore the advantages or disadvantages faced by teachers so that they can be training for the technologies that facilitate both themselves and their students to achieve the best possible result for the students' benefits.

\section{REFERENCES}

1. National Research Council (NRC). (2012). A framework for K-12 science education: Practices, crosscutting concepts, and core ideas. Committee on Conceptual Framework for the New K-12 Science Education Standards. Board on Science Education. Division of Behavioral and Social Sciences and Education. Washington, DC: The National Academies Press.

2. Shwartz, Y., Weizman, A., Fortus, D., Krajcik, J., \& Reiser, B. (2008). The IQWST experience: Using coherence as a design principle for a middle school science curriculum. The Elementary School Journal, 109(2), pp. 199-219.

3. Driver, R., Squires, A., Rushworth, P., \& Wood-Robinson, V. (2014). Making sense of secondary science: Research into children's ideas. London: Routledge

4. Kirch, S., Bargerhuff, M. E., \& Cowan, H. (2007, July). Inclusive Science Education: Classroom Teacher and Science Educator Experiences in CLASS Workshops. In FIRST INTERNATIONAL CONFERENCE ON TECHNOLOGY-BASED LEARNING WITH DISABILITY (pp. 102-111). Dayton, Ohio: Wright State University.

5. Hilliard, L., Dunston, P., McGlothlin, J., \& Duerstock, B. S. (2013). Designing beyond the ADA-creating an accessible research laboratory for students and scientists with physical disabilities. In RESNA Conference. Washington: RESNA(Rehabilitation Engineering and Assistive Technology Society of North America).

6. Hadi, A., Yusop, M., Mohamad, B., \& Jaafar, M. S. A. (2010). Study of information and communication technology (ICT) usage in technical and vocational special education programme. Global Journal of Human Social Science Research, 10(1), pp. 35-43

7. Liu, J., \& Tomasi, S. D. (2015). The Effect of Professor's Attractiveness on Distance Learning Students. Journal of Educators Online, 12(2), pp. 142-165.
Ma \& Zhang,2019[40] ) their good performance due to

8. Chantry, J., \& Dunford, C. (2010). How do computer assistive technologies enhance participation in childhood occupations for children with multiple and complex disabilities? A review of the current literature. British Journal of Occupational Therapy, 73(8), pp. 351-365. https://doi.org/10.4276/030802210X12813483277107

9. Drigas, A., Ioannidou, R. E., Kokkalia, G., \& Lytras, M. D. (2014). ICTs, mobile learning and social media to enhance learning for attention difficulties. J. UCS, 20(10), pp. 1499-1510.

10. Lawanto, O., Santoso, H. B., Lawanto, K. N., \& Goodridge, W. (2017) Self-regulated learning skills and online activities between higher and lower performers on a web-intensive undergraduate engineering course. Journal of Educators Online, 11(3), n3.

11. Selvakumar, S., \& Sivakumar, P. (2019). The Impact of Blended Learning Environment on Academic Achievement of Engineering Students. International Journal of Innovative Technology and Exploring Engineering,8(12), pp. 3782-3787.

12. Nefediev, V. V., Grishina, V. T., Suvorova, E. V., Rebrikova, N. V., \& Matveeva, O. Z. (2019). The Role of E-Learning in the Implementation of Innovative Educational Technologies. International Journal of Innovative Technology and Exploring Engineering, 8(7), pp. 23802384.

13. Huda, M., Hashim, A., Teh, K. S. M., Shankar, K., Ayshwarya, B., Nguyen, P. T., ... \& Maseleno, A. (2019). Learning quality innovation through integration of pedagogical skill and adaptive technology. International Journal of Innovative Technology and Exploring Engineering, 8(9S3), pp. 1538-1541.

14. Wikan, G., \& Molster, T. (2011). Norwegian secondary school teachers and ICT. European Journal of Teacher Education, 34(2), pp. 209-218.

15. Judge, M. (2013). Mapping out the ICT integration terrain in the school context: identifying the challenges in an innovative project. Iris $h$ Educational Studies, 32(3), pp. 309-333.

16. UNESCO(2011) ICTs in education for people with disabilities .Review of innovative practice. Moscow: UNESCO Institute for Information Technologies in Education.

17. Nam, C. S., Bahn, S., \& Lee, R. (2013). Acceptance of assistive technology by special education teachers: A structural equation model approach. International Journal of Human-Computer Interaction, 29(5), pp. 365-377.

18. Istenic Starcic, A., \& Bagon, S. (2014). ICT-supported learning for inclusion of people with special needs: Review of seven educational technology journals, 1970-2011. British Journal of Educational Technology, 45(2), pp. 202-230.

19. Zamfirov, M., Saeva, S., \& Popov, T. (2007). Innovation in teaching deaf students physics and astronomy in Bulgaria. Physics education, 42(1), pp. 98-104 https://doi.org/10.1088/0031-9120/42/1/014.

20. Robinson V.(2013 )Teaching Physics to Deaf College Students In A 3D Virtual Lab. Journal of Science Education for Students with Disabilitie17(1), pp. 41-52

21. Egelston-Dodd, J., \& Ting, S. (2007). Video-Tutorials for Tech Sign Vocabulary in Astronomy. Journal of Science Education for Students with Disabilities, 12(1), pp. 21-26

22. Bogusevschi, D., Tal, I., Bratu, M., Gornea, B., Caraman, D., Ghergulescu, I., ... \& Muntean, G. M. (2018, June). Water cycle in nature: small-scale STEM education pilot. Association for the Advancement of Computing in Education (AACE). In EdMedia+ Innovate Learning pp. 1496-1505.

23. Jaramillo-Alcázar, A., Guaita, C., Rosero, J. L., \& Luján-Mora, S (2018, June). An approach to Inclusive Education in Electronic Engineering Through Serious Games. In 2018 XIII Technologies Applied to Electronics Teaching Conference (TAEE) IEEE. (pp. 1-7) IEEE (Institute of Electrical and Electronics Engineers) DOI: 10.1109/TAEE.2018.8476110

24. Choiriyah, N. (2015). Developing of interactive e-book media on subject matter of chemicals in daily life for high school deaf studenat. UNESA Journal of Chemical Education, 4(1), pp.119-125.

25. Goncalves, A. M. B., Cena, C. R., Alves, D. C. B., Errobidart, N. C. G. Jardim, M. I. A., \& Queiros, W. P. (2017). Simple pendulum for blind students. Physics Education, 52(5), 053002 https://doi.org/10.1088/1361-6552/aa79c2

26. Qutieshat, A., Aouididi, R., \& Arfaoui, R. (2019). Design and Construction of a Low-Cost Arduino-Based pH Sensor for the Visually Impaired Using Universal pH Paper. Journal of chemical education, 96(10), pp. 2333-2338. DOI: 10.1021/acs.jchemed.9b00450

27. Quinn, M. (2012). "Walk on the Sun": an interactive image sonification exhibit. AI \& society, 27(2), pp. 303-305. DOI $10.1007 / \mathrm{s} 00146-$ 011-0355-1

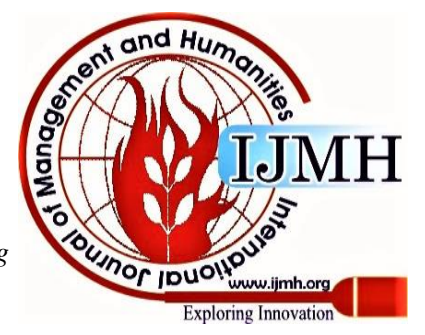


28. Morgan,E., Moore,E.(2016) Investigating Student Learning with Accessible Interactive Physics Simulations. Published by the American Association of Physics Teachers under a Creative Commons Attribution 3.0 license. doi:10.1119/perc.2016.pr.053

29. Cole, R. A., \& Slavin, A. J. (2013). Use of a video assistive device in university course in laboratory science: A case study. Journal of Visual Impairment \& Blindness, 107(4), pp. 311-315.

30. Nazemi, A., McMeekin, D. A., \& Murray, I. (2015). Unbalanced chemical equations conversion to mark-up format and representation to vision impaired students. Computer Applications in Engineering Education, 23(6), pp. 805-812. http://doi.org/10.1002/cae.21651.

31. Tsavli, M., Fragakis, J., Kopsidas, S., Zisiadis, D., \& Vavougios, D. (2009). Integrated ICT System for Teaching Physical Sciences in a Robotic Laboratory. International Journal of Emerging Technologies in Learning, 4. Special Issue 3: "ICL2009",67-73 doi:10.3991/ijet.v4s3.1118

32. Duarte, M., Butz, B. P., Miller, S. M., \& Mahalingam, A. (2008). An intelligent universal virtual laboratory (UVL). IEEE transactions on education, 51(1), pp. 2-9.

33. Gerhátová, Ž. (2014). Experiments on the Internet-removing barriers facing students with special needs. Procedia-Social and Behavioral Sciences, 114, pp. 360-364. doi: 10.1016/j.sbspro.2013.12.712

34. Kyriakou, T., Charitaki, G., \& Kotsopoulou, A. (2015). Multi-Sensory Approach through the Use of ICT for the School Inclusion of a Child with Down syndrome. Procedia Computer Science, 65, pp. 158-167. doi: 10.1016/j.procs.2015.09.104

35. Tomlinson, B. J., Kaini, P., Walker, B. N., Batterman, J. M., \& Moore, E. B. (2018). Supporting Simulation Use for Students with Intellectual and Developmental Disabilities. Journal on Technology and Persons with Disabilities 6, pp. 202-218.

36. Kim, M. S. (2017). Multimodal Modeling Activities with Special Needs Students in an Informal Learning Context: Vygotsky Revisited. Eurasia Journal of Mathematics, Science and Technology Education, 13(6), pp. 2133-2154.

37. Marino, M. T., Gotch, C. M., Israel, M., Vasquez III, E., Basham, J. D., \& Becht, K. (2014). UDL in the middle school science classroom: Can video games and alternative text heighten engagement and learning for students with learning disabilities?. Learning Disability Quarterly, 37(2), pp. 87-99.

38. Marino, M. T., Basham, J. D., \& Beecher, C. C. (2011). Using video games as an alternative science assessment for students with disabilities and at-risk learners. Science Scope, 34(5), pp. 36-41

39. Vassilopoulou, A., \& Mavrikaki, E. (2016). Can ICT in biology courses improve AD/HD students' achievement?. Improving Schools, 19(3), pp. 246-257. https://doi.org/10.1177/1365480216647144

40. Ma, L., \& Zhang, J. (2019, June). Exploration and Practice of College Physics Teaching for Students with Learning Difficulties. In Proceedings of the 5th International Conference on Frontiers of Educational Technologies (pp. 93-96). DOI: https://doi.org/10.1145/3338188.3338199

41. Baumann, T., \& Melle, I. (2019). Evaluation of a digital UDL-based learning environment in inclusive chemistry education. Chemistry Teacher International, 1(2).

42. Cecil, J., Sweet-Darter, M., \& Cecil-Xavier, A. (2017, October) Exploring the use of virtual learning environments to support science learning in autistic students. In 2017 IEEE Frontiers in Education Conference (FIE) (pp. 1-8). IEEE.

43. Tolentino, L., Birchfield, D., \& Kelliher, A. (2009, January). SMALLab for special needs: Using a mixed-reality platform to explore learning for children with autism. In Proceedings of the NSF Media Arts, Science and Technology Conference, Santa Barbara, CA, USA (pp. 29-30).

44. King-Sears, M. E., Johnson, T. M., Berkeley, S., Weiss, M. P., PetersBurton, E. E., Evmenova, A. S., ... \& Hursh, J. C. (2015). An exploratory study of universal design for teaching chemistry to students with and without disabilities. Learning Disability Quarterly, 38(2), 8496.

45. Wedler, H. B., Boyes, L., Davis, R. L., Flynn, D., Franz, A., Hamann, C. S., ... \& Tantillo, D. J. (2014). Nobody can see atoms: science camps highlighting approaches for making chemistry accessible to blind and visually impaired students. Journal of Chemical Education, 91(2), pp. 188-194.

46. Supalo, C. A., Mallouk, T. E., Amorosi, C., Lanouette, J., Wohlers, H. D., \& McEnnis, K. (2009). Using adaptive tools and techniques to teach a class of students who are blind or low-vision. Journal of chemical Education, 86(5), pp. 587-591

\section{AUTHORS PROFILE}

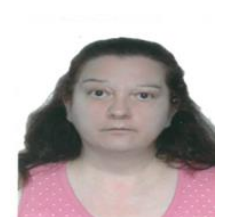

Maria-Theofania Kontopoulou, (graduate physicists) is physics teacher and has M.Sc in "Information and Communication Technologies (ICTs) and Special Education”. She has participated in variousresearch projects regarding the use of Information andCommunication Technologies (ICTs) in Physics teaching. She is also a scientific collaborator of N.C.S.R. 'Demokritos', Institute of Informatics and Telecommunications - Net Media Lab \& Mind-Brain R\&D, Agia Paraskevi, 153 10, Athens, Greece (e-mail:mariairakleio@yahoo.gr).

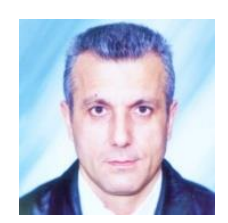

Athanasios Drigas, is a Research Director at N.C.S.R. 'Demokritos', Institute of Informatics and Telecommunications, 153 10, Athens, Greece. He is the Coordinator of Net Media Lab \& Mind-Brain R\&D. He has Coordinated Several International Projects, in the fields of Cognition and e-services (epsychology,e-inclusion,e-learning, e-government, eculture etc.). He has published more than 320 articles, 7 books, 25 educational CD-ROMs and severalpatents.E-mail: dr@iit.demokritos.gr).

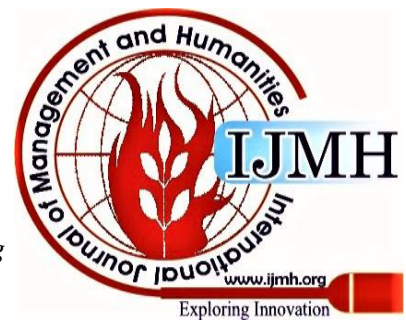

